\title{
Study on extraction phenol from coal tar with high flux centrifugal extractor
}

\author{
Yuan Zhao ${ }^{1,2,3} \cdot$ Xuefeng Mao ${ }^{1,2,3} \cdot$ Weilin $\mathrm{Li}^{1,2,3} \cdot$ Xiaohui Gu ${ }^{1,2,3} \cdot$ Guangyao Wang ${ }^{1,2,3}$
}

Received: 9 March 2017/Revised: 15 July 2017/Accepted: 17 August 2017/Published online: 2 September 2017

(C) The Author(s) 2017. This article is an open access publication

\begin{abstract}
Solvent extraction phenol from coal tar were carried out with novel composite YH-3 as extraction agent, and the high flux centrifugal extractor was used as extraction device. Under the premise of high phenol extraction rate, composite YH-3 extraction agent reduces $\pi-\pi$ interaction between phenolic compounds and aromatic hydrocarbons, thus decreasing the entrainment of neutral oil. The optimization of operation conditions, such as the diameter of heavy phase weir HWD, the flow ratio, the total flow rate and the rotation speed, are necessary. For single stage extraction experiment, the mass transfer efficiency was up to $84 \%$ while the rate of extraction agent loss was lower than $0.28 \%$ with the operation conditions of $29 \mathrm{~mm}$ of the heavy phase weir diameter (HWD), 1:1-1.4:1 of the flow ratio range, $160-200 \mathrm{~mL} / \mathrm{min}$ of the total flow rate and the rotation speed varied from 2200 to $2600 \mathrm{r} / \mathrm{min}$. For three stage counter-current test, the mass transfer efficiency reached up to $92.6 \%$ with the optimum operation condition of $29 \mathrm{~mm}$ of the HWD, 1:1 of the flow ratio, $200 \mathrm{~mL} / \mathrm{min}$ of the total flow rate and $2400 \mathrm{r} / \mathrm{min}$ of the rotation speed. The results indicated that phenol could be extracted effectively from coal tar in the process of multistage continuous count current centrifugal extraction.
\end{abstract}

Keywords High flux centrifugal extractor $\cdot$ Coal tar $\cdot$ Phenol $\cdot$ Mass transfer efficiency $\cdot$ Loss rate

\section{Introduction}

As a valuable raw material and an important fine chemical intermediate, phenol compounds are widely used in pesticide, medicine, dyestuff and spices industry, which have high economic value (Ge and Jin 1995; Xue et al. 1998; Li et al. 2005; Liu et al. 2012). Because coal tar contains significant amounts of phenol compounds, especially in middle and low temperature coal tar, the research on

Yuan Zhao

zhao-yuan11@163.com

1 Beijing Research Institute of Coal Chemistry, China Coal Research Institute, Beijing 100013, China

2 National Energy Technology and Equipment Laboratory of Coal Utilization and Emission Control, Beijing 100013, China

3 State Key Laboratory of Coal Mining and Clean Utilization, Beijing 100013, China extraction phenol from coal tar posse significant economic benefits.

The study of extraction phenol from coal tar is mainly based on the properties of polarity and acid. The mature alkali wash method, which is widely used in industry, is based on the acid properties of phenol compounds. However, the alkali washing method has some obvious drawbacks, including easy emulsification, equipment corrosion problems and serious pollution (Liu and Qang 2001; Jia and Jia 2008; Ye et al. 2010; Wang et al. 2011). The solvent extraction method is based on the polarity property of phenol, which will be the developing direction of extraction phenol from coal tar, and it has many advantages, such as low price, nontoxic extraction agent, corrosion-free, moderate operation conditions, no waste water and no exhaust gas in the course of production (Tiwari and Sen 1991; Wu et al. 2001; Liu and Xie 2014). The extraction method has been used in industry (Zong et al. 2013), yet the most adopted solvent extraction equipment is the mixer-settler, which have obvious disadvantages of large 
liquid holdup, significant solvent loss, long mixing and refining time, large land occupied and only intermittent operation. In contrast, centrifugal extractor has many advantages, such as compact structure, high treatment capacity, low liquid holdup, high mass transfer effect, convenient for starting and stopping, remote automatic control (Leonard et al. 1997; Fu 2004; Li and Yuan 2007). With the above advantages, some chemical plants have begun to treat phenol waste water with the centrifugal extractor (Xu et al. 1999; Yu et al. 2001; Wang et al. 2001; Tang et al. 2012; Mishra et al. 2016).

However, there are little systematic research on extracting phenol from coal tar with centrifugal extractor. In order to get rid of the drawbacks of annulus centrifugal extractor, such as high energy consumption, complex structure and hard dismantling (Chen et al. 2009; Yuan et al. 2010; Wang 2014; Li et al. 2016), the extraction phenol from coal tar by new-type high flux centrifugal extractor were systematically studied in this paper.

\section{Experimental}

\subsection{Structure and work principle of $\mathrm{HCE}$}

Structure of HCE is shown in Fig. 1.

High flux centrifugal extractor is composed of housing, rotary drum and mixing chamber. The rotating shaft connects with the drum. The heavy phase weir is arranged on the top of drum, and can be directly replaced without removing the drum from extractor. The mixer is arranged at the bottom of drum, which is located in mixing chamber. Heavy and light phase collecting chamber are set up between drum and lining. The whole centrifuge is equipped with suspension structure, without bottom bearings and

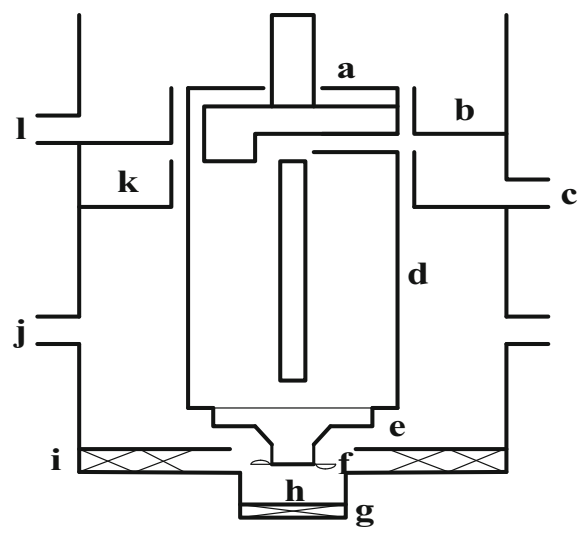

Fig. 1 Structure schematic drawing of HCE. $a$ heavy phase weir, $b$ heavy phase collecting chamber, $c$ light phase outlet, $d$ drum, $e$ feed terminal, $f$ mixer, $g$ feed guide vane, $h$ mixing chamber, $i$ vortex guide vane, $j$ feed inlet, $k$ light phase collecting chamber, and $l$ heavy phase outlet mechanical seals. So, the centrifuge is in the status of low power consumption and low failure rate. The device can control the particle size of the droplet through the special mixing blade, so as to avoid emulsification. The main parameter of centrifugal extractor: diameter of rotating drum: $50 \mathrm{~mm}$, length of rotating drum: $140 \mathrm{~mm}$, output frequency: $40 \mathrm{~Hz}$, separating factor: $0-1000$ and rated flux (two phase mixing flux): 0-20 L/h (Figs. 2, 3).

Extraction agent and raw oil enter the extractor from both sides of the feed inlet as a quantitative flow. Two phases flowed into the mixing chamber under the influence of gravity, mixed thoroughly with mixer, then entered into the drum through feed terminal. Finally, mixed phase was separated in the drum by centrifugal force. Heavy phase was thrown to the wall of the drum, clusters into a group, and flowed out through heavy collecting chamber and outlet. On the contrary, light phase gathered in the central regions of the drum, and flowed out through light collecting chamber.

\subsection{Experimental raw materials}

Typical medium and low temperature coal tar was selected as experiment material. Firstly, $170-230{ }^{\circ} \mathrm{C}$ fraction was obtained via distillation under vacuum. Secondly, density of the fraction was measured under normal temperature, phenol compounds content in the fraction was determined by using the standardization method of "Determination of the phenol content of washing oil" GB/T24207-2009.

The acidic components in the raw material were concentrated by means of alkali washing and acid extraction, then were analyzed qualitatively and quantitatively by the gas chromatograph using external standard method. The experimental conditions were as follows: capillary chromatographic column model of DB Petro-122-10A6 $(100.0 \mathrm{~m} \times 0.25 \mathrm{mmID} \times 0.5 \mu \mathrm{mdf})$, FID detector, inlet temperature of $280{ }^{\circ} \mathrm{C}$, detector temperature of $300{ }^{\circ} \mathrm{C}$. Heating procedures were as follows: oven temperature stayed at $70{ }^{\circ} \mathrm{C}$ for $2 \mathrm{~min}$, then increased up to $200{ }^{\circ} \mathrm{C}$ at a rate of $4{ }^{\circ} \mathrm{C}$ per minute, stayed for $4 \mathrm{~min}$ and finally increased up to $280{ }^{\circ} \mathrm{C}$ at a rate of $2{ }^{\circ} \mathrm{C}$ per minute.

The neutral oil components were enriched by alkali washing, then were qualitatively analyzed by gas chromatographic-mass spectrometer (GC-MS). The experimental conditions were as follows: inlet and detector temperature of $300{ }^{\circ} \mathrm{C}$, interface temperature of $320{ }^{\circ} \mathrm{C}$, ionization source of EI, electron energy of $70 \mathrm{eV}$, the ionization temperature of $240{ }^{\circ} \mathrm{C}$. Heating procedures were as follows: oven temperature stayed at $70{ }^{\circ} \mathrm{C}$ for $5 \mathrm{~min}$, then increased up to $170^{\circ}$ at a rate of $4{ }^{\circ} \mathrm{C}$ per minute, stayed for $3 \mathrm{~min}$ and finally increased up to $280^{\circ}$ at a rate of $2{ }^{\circ} \mathrm{C}$ per minute. 


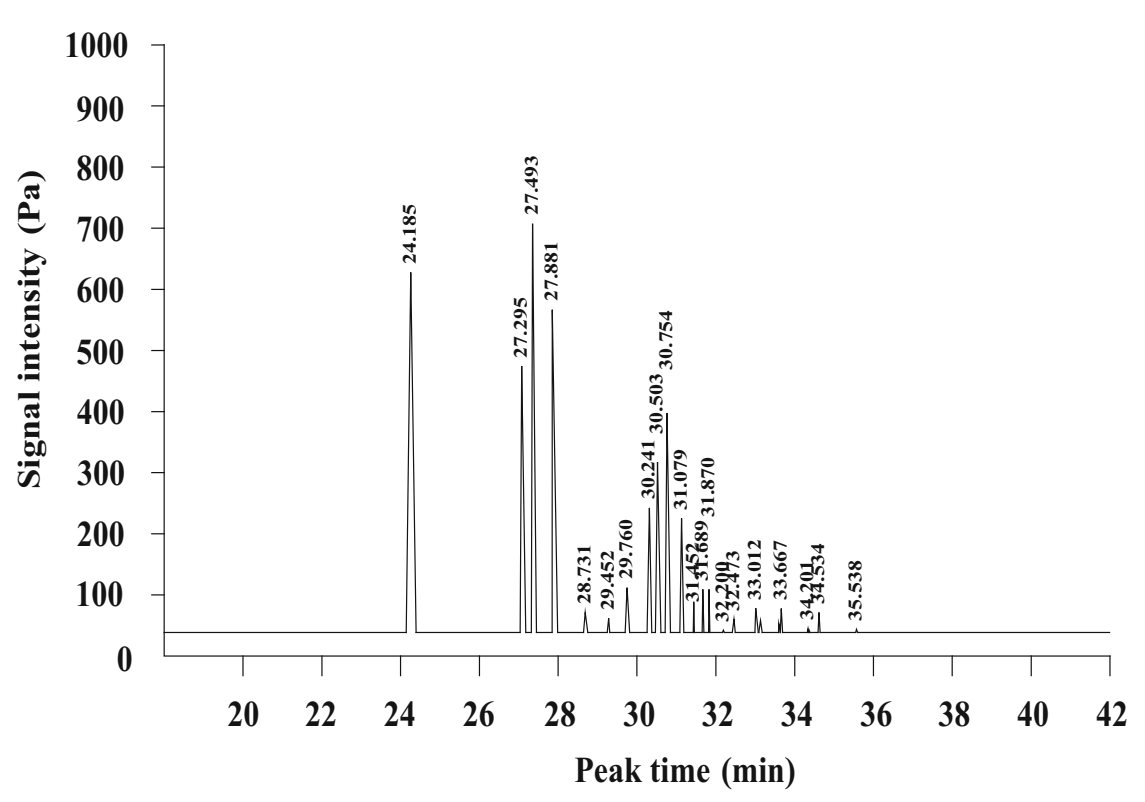

Fig. 2 Chromatography of acidic components in the medium and low temperature coal tar

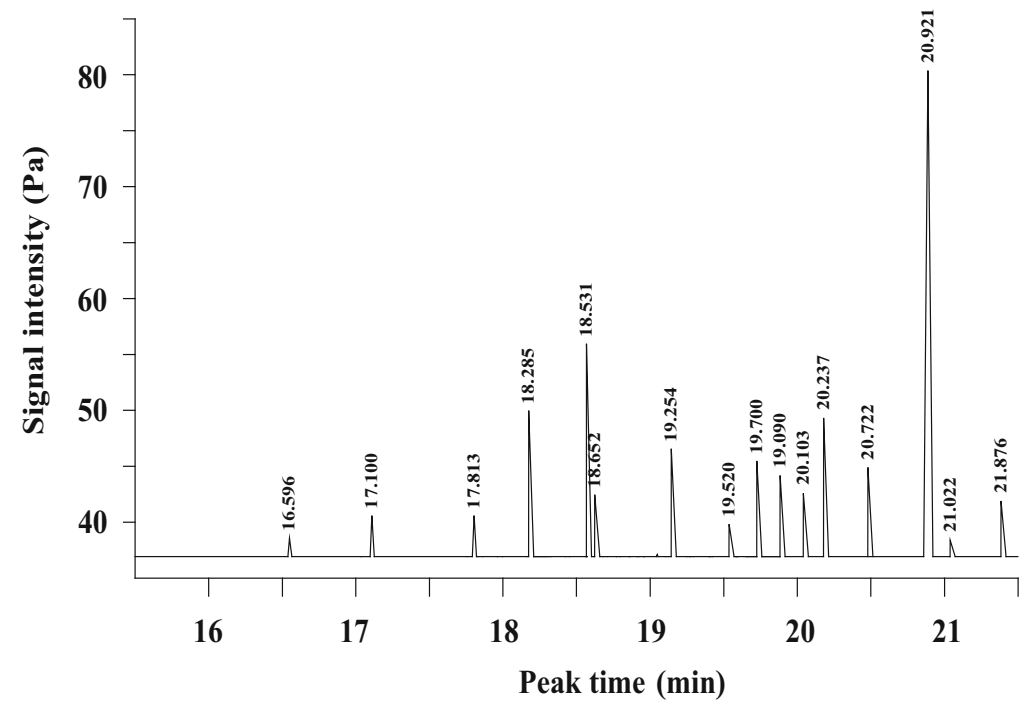

Fig. 3 Chromatography of neutral oils in the medium and low temperature coal tar

\subsection{Analysis methods}

The phenol compounds contents in raw oil and light phase are determined by the standardization method of "Determination of the phenol content of washing oil". The mass transfer efficiency of centrifugal extractor ( $E$ as phenol extraction efficiency) is calculated with Formula (1):

$E=\left(\frac{C_{\text {in }}-C_{\text {out }}}{C_{\text {in }}}\right) \times 100 \%$

where $C_{\text {in }}, C_{\text {out }}$ are phenol mass content of raw oil and light phase respectively.
Extraction agent mass content of light phase is determined with the gas chromatograph using external standard method. The loss rate of extraction agent $\left(E_{\mathrm{s}}\right)$ is calculated with Formula (2), thus the index is used as a basis for the judging entrainment phenomenon.

$E_{\mathrm{s}}=\left(\frac{m_{\mathrm{o}} \times C_{\mathrm{s}}}{m_{\mathrm{s}}}\right) \times 100 \%$

where $m_{\mathrm{s}}$ is the mass of extraction agent feed into HCE, $m_{\mathrm{o}}$ and $C_{\mathrm{s}}$ are the mass and extraction agent mass content of the light phase (Table 1). 
Table 1 Qualitative and quantitative analysis of acidic components in the coal tar

\begin{tabular}{|c|c|c|c|}
\hline $\begin{array}{l}\text { Phenolic } \\
\text { compounds }\end{array}$ & $\begin{array}{l}\text { Mass } \\
\text { fraction (\%) }\end{array}$ & Phenolic compounds & $\begin{array}{l}\text { Mass } \\
\text { fraction }(\%)\end{array}$ \\
\hline Phenol & 8.95 & 3,4-Dimethyl phenol & 2.31 \\
\hline o-Cresol & 9.09 & 2-Propylphenol & 0.22 \\
\hline m-Cresol & 13.41 & 4-Isopropenylphenol & 1.35 \\
\hline p-Cresol & 9.24 & $\begin{array}{l}\text { 2,4,6- } \\
\text { Trimethylphenol }\end{array}$ & 0.25 \\
\hline 2-Ethylphenol & 2.09 & 4-Propylphenol & 0.96 \\
\hline $\begin{array}{l}\text { 2,5-Dimethyl } \\
\text { phenol }\end{array}$ & 3.58 & $\begin{array}{l}\text { 2,3,5- } \\
\quad \text { Trimethylphenol }\end{array}$ & 1.37 \\
\hline 3-Ethylphenol & 6.28 & $\begin{array}{l}\text { 2,3,6- } \\
\text { Trimethylphenol }\end{array}$ & 0.13 \\
\hline $\begin{array}{l}\text { 2,4-Dimethyl } \\
\text { phenol }\end{array}$ & 6.22 & $\begin{array}{l}\text { 3,4,5- } \\
\quad \text { Trimethylphenol }\end{array}$ & 0.01 \\
\hline 4-Ethylphenol & 3.43 & 1-Naphthol & 0.11 \\
\hline $\begin{array}{l}\text { 2,6-Dimethyl } \\
\text { phenol }\end{array}$ & 2.64 & 2-Naphthol & 0.02 \\
\hline $\begin{array}{l}\text { 2,3-Dimethyl } \\
\text { phenol }\end{array}$ & 1.30 & $\begin{array}{l}\text { Unidentified } \\
\text { components }\end{array}$ & 27.04 \\
\hline
\end{tabular}

Table 2 Retrieval results of major neutral oil compound

\begin{tabular}{lll}
\hline $\begin{array}{l}\text { Retention time } \\
t_{\mathrm{R}}(\min )\end{array}$ & $\begin{array}{l}\text { Retrieved } \\
\text { compounds }\end{array}$ & $\begin{array}{l}\text { Relative molecular } \\
\text { mass }\end{array}$ \\
\hline 18.531 & Indene & 116 \\
20.237 & Methyl indane & 132 \\
20.921 & Naphthalene & 128 \\
21.876 & Methylnaphthalene & 142 \\
\hline
\end{tabular}

\section{Results and discussion}

\subsection{Analysis of raw materials and development of composite extractant}

The chromatogram of acidic components in the medium and low temperature coal tar was as follows:

Phenolic compounds were identified $73 \%$ of the total acidic components, of which phenol and cresol accounted for about $40.69 \%$, ethyl phenol and dimethyl phenol accounted for $23.91 \%$. In summary, the lower-grade phenols content was relatively high.

The retrieved main neutral oils were listed in Table 2. The mass spectra of neutral oils were shown in Fig. 4.

The analysis results showed that the neutral oils of coal tar extraction material were mainly single or double ring aromatic hydrocarbon, due to interactions of $\pi-\pi$ bond between phenolic compounds and aromatic hydrocarbons, single extractant was difficult to ensure the high extraction rate of phenol in the condition of high selectivity, therefore (a)

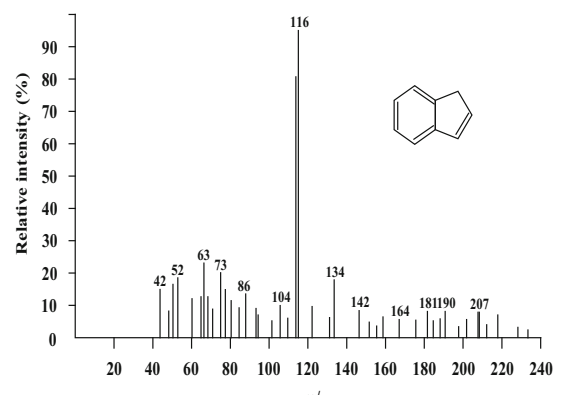

(b)

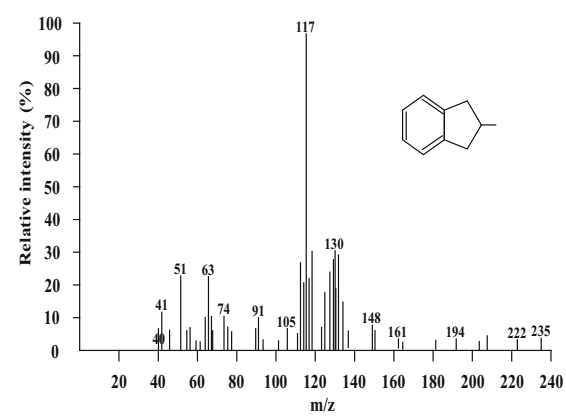

(c)

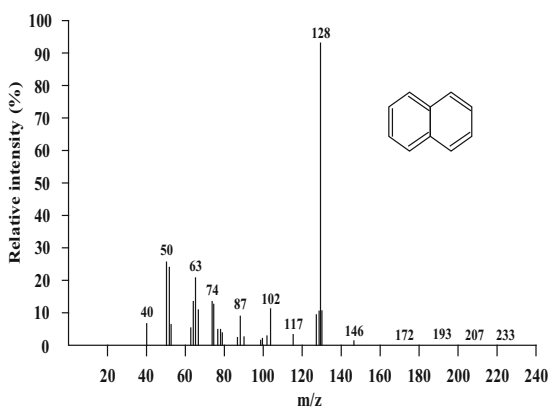

(d)

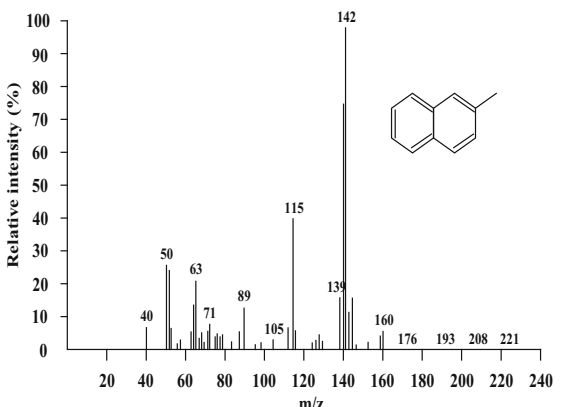

Fig. 4 MS spectrum of major neutral oil compounds. a Mass spectrum of Indene. b Mass spectrum of Methyl indane. c Mass spectrum of Naphthalene. d Mass spectrum of Methylnaphthalene

composite and highly effective phenol extraction agent YH-3 needed to be developed. According to polarity character and hydrogen bond interaction of phenolic compounds, an alcohol solvent was selected as a base extractant, and a kind of alkane compound with a large group is added. The alkane compound could increase the steric hindrance between the benzene rings and weak the 
$\pi-\pi$ interaction, thus the amount of neutral oil entrained was effectively reduced (Figs. 5, 6).

The results of qualitative and quantitative analysis to extraction phenol showed that the effective enrichment of the lower phenol was achieved by extraction, especially for phenol and cresol. Under the condition of ensuring the extraction efficiency, the entrainment rate of naphthalene (retention time was $29.45 \mathrm{~min}$ ) and $\alpha$-methyl naphthalene (retention time was $34.20 \mathrm{~min}$ ) was effectively decreased.

The value of HWD was set as $29.0 \mathrm{~mm}$, according to the density and viscosity of raw oil and extraction agent. In this context, entrainment phenomenon was avoided by regulating the rotation speed.

\subsection{Influence of flow ratio on the mass transfer efficiency and loss rate of extraction agent}

The samples in each condition experiments were collected from heavy and light phase outlet after total transition flow reached $800 \mathrm{~mL}$. The effects of flow ratio on the mass transfer efficiency and rate of extraction agent loss were investigated under the fixed conditions including $200 \mathrm{~mL} /$ min of total flow rate and $2400 \mathrm{r} / \mathrm{min}$ of rotation speed.

According to the above figure, when the volume ratio of solvent agent to feed was in the range of $0.6-2.6: 1$, the mass transfer efficiency was up to $80 \%$, which increased firstly, then decreased with the increasing of flow ratio. Because the total phenol content in raw feed was high, all phenol could not be extracted completely, given that the

(a)

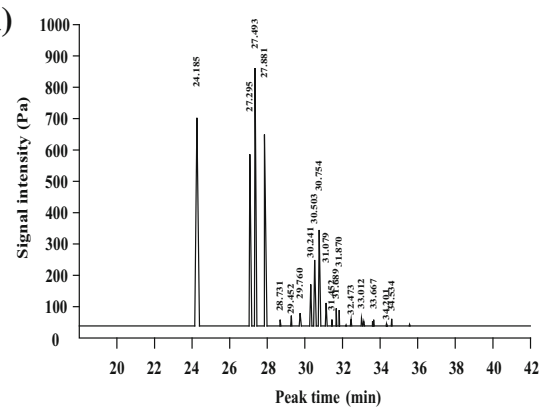

(b)

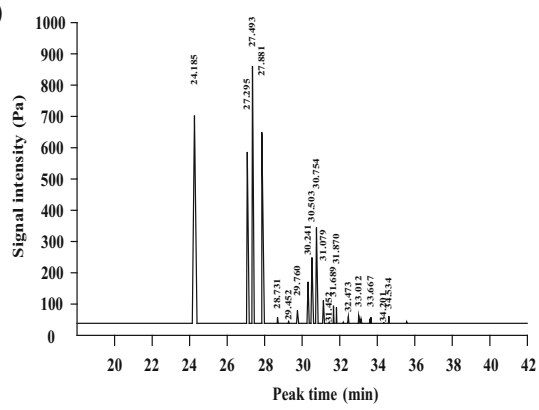

Fig. 5 Chromatography of solvent extraction phenol. a Chromatography of single solvent extraction phenol. b Chromatography of composite solvent extraction phenol feeding rate of solvent agent was low. However, the mass transfer efficiency decreased with the increasing of flow ratio, when the feed quantity of solvent agent was enough. The reason for the above phenomenon might be explained with the following description. A phase was dispersed in the form of liquid droplets in another in HCE equipment. The size of the interface area in per unit volume of mixed phase was determined by the average diameters of droplets and the holdup of dispersed phase. When other processing parameters were fixed, the holdup of dispersed phase and the interface area in per unit volume of mixed phase were both small under the condition of high volume ratio of solvent agent to feed. Furthermore, with the increasing of phase ratio, the result easily leaded to mix unevenly and decreased the interface area, thus mass transmission and mass transfer efficiency decreased due to the influence of limited phase contact time.

The rate of extraction agent loss showed the trend of increase, with the increasing of flow ratio of solvent agent to feed. When the flow ratio was more than 1.8 , the loss rate was significantly increased. The increasing of flow ratio corresponded to the increasing of the solvent agent volume fraction in per unit volume. While the volume fraction of solvent agent was controlled within a rational range, light and heavy phase could be efficiently separated in a relatively short residence time, and the entrainment rate of solvent agent rates was ensured at a low level. When the volume fraction further increased, the amount of heavy phase increased correspondingly. The phase interface moved towards the device center, then light phase layer then enforced to be thinner, and flowed into the light phase overflow weir together with entrainment heavy phase easily. Consequently, the loss rate of solvent agent significantly increased. Overall, the optimum range of flow ratio was $1-1.4: 1$.

\subsection{Influence of total flow rate on the mass transfer efficiency and loss rate of extraction agent}

The effects of total flow rate on the mass transfer efficiency and loss rate of extraction agent were investigated under the fixed conditions including 1:1 of flow ratio and $2400 \mathrm{r} /$ min of rotation speed.

Figure 7 showed that the mass transfer efficiency decreased gradually with the increasing of total flow rate of raw material and solvent agent. When total flow rate was more than $200 \mathrm{~mL} / \mathrm{min}$, the mass transfer efficiency was dramatically reduced. Once the flow rate was up to $320 \mathrm{~mL} / \mathrm{min}$, the mass transfer efficiency was less than $80 \%$. The major reason for above phenomenon was two phase finite contact time. When valid volume of HCE was fixed, with the increasing of total flow rate, the average residence and mixing time of two phase in HCE became 


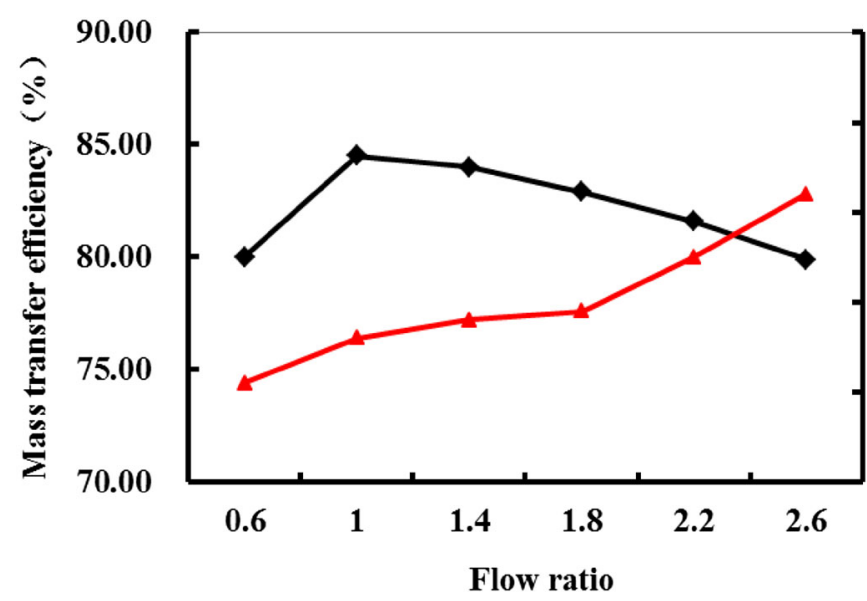

0.60

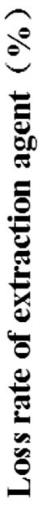

Fig. 6 Influence of flow ratio on the mass transfer efficiency and loss rate of extraction agent

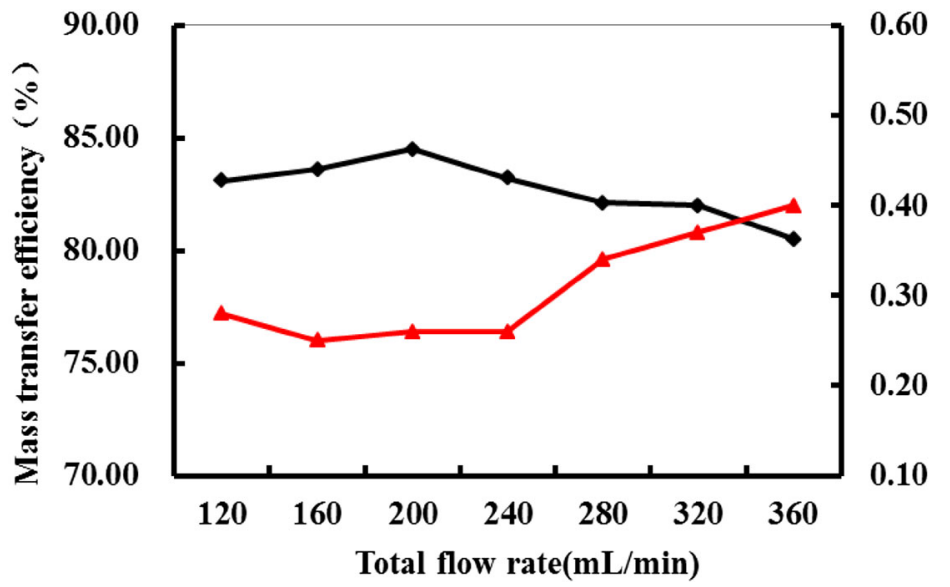

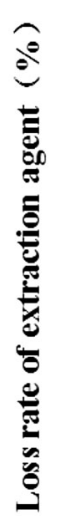

Fig. 7 Influence of total flow rate on the mass transfer efficiency and loss rate of extraction agent

shorter. Meanwhile, when rotate speed was fixed, the total input power kept constant. When total flow rate was increasing, the input power of mixed phase in per unit volume decreased, the mixed-degree was obviously reduced. Accordingly, with the increasing of total flow rate, the mass transfer efficiency decreased.

The rate of solvent agent loss showed a rising trend with the increasing of total flow rate. When the total flow rate was more than $240 \mathrm{~mL} / \mathrm{min}$, the loss rate was dramatically increased. The separation performance of HCE was attached to residence time. Given enough time, the process finished well, which the heavy phase moved towards the walls, and the light phase moves towards the center of HCE respectively. Under the condition of low total flow rate, the residence time was long enough to separate effectively, so the loss rate of extraction agent was small. On the contrary, the residence time became shorter with the increasing of total flow rate. The short residence time corresponded to short separation time. It aroused the deteriorating separation performance. Therefore, the smaller the total flow rate, the better the separation efficiency, the lower the loss rate of extraction agent. Ultimately, the optimum range of total flow rate was 160-240 mL/min (Figs. 8, 9).

\subsection{Influence of rotation speed on the mass transfer efficiency and loss rate of extraction agent}

The effects of rotation speed on the mass transfer efficiency and loss rate of extraction agent were investigated under the fixed conditions including $200 \mathrm{~mL} / \mathrm{min}$ of total flow rate and $1: 1$ of flow ratio.

According to the above figure, under the conditions of fixed total flow rate and flow ratio, the effect of rotation speed on the mass transfer efficiency was investigated. The adjustment range of rotary speed was 1800-2800 r/min. With the increasing of rotary speed, the mass transfer efficiency showed the trend of first increase and then decrease. When the rotation speed achieved about $2400 \mathrm{r} / \mathrm{min}$, the efficiency reached the maximum. Because the rotational speed was low, the input power was a little, and the mixing 


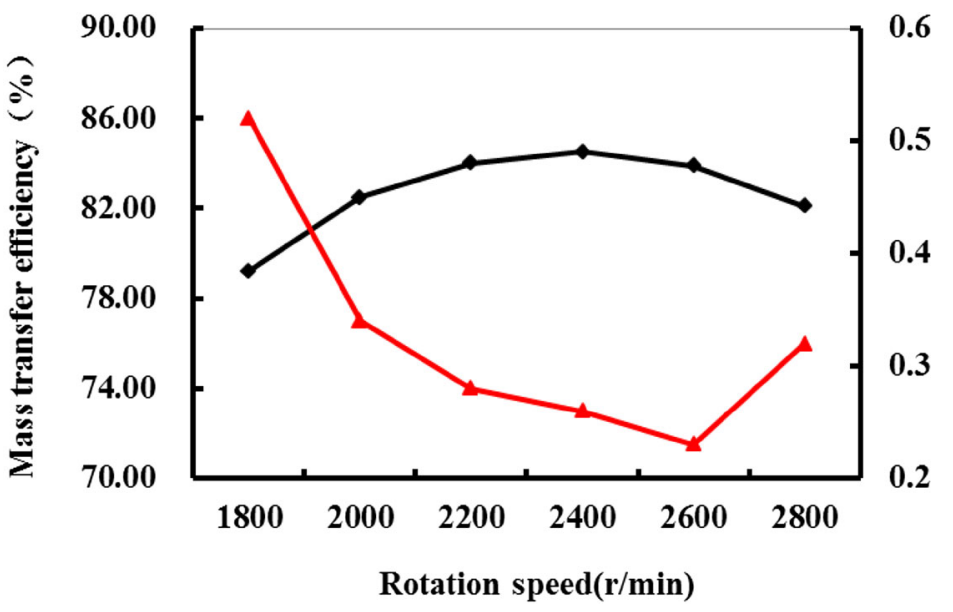

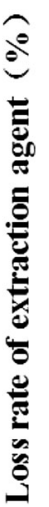

Fig. 8 Influence of rotation speed on the mass transfer efficiency and loss rate of extraction agent

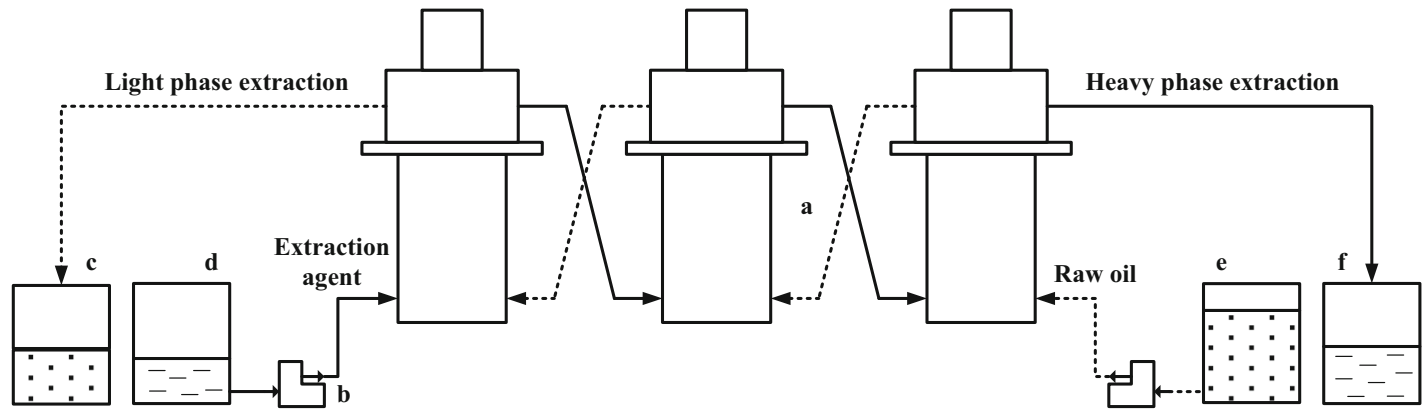

Fig. 9 Work flow diagram of three stages counter current extraction. $a$ high flux centrifugal extractor, $b$ feed creeping pump, $c$ light phase storage tank, $d$ extractor agent storage tank, $e$ raw oil storage tank, and $f$ heavy phase storage tank

intensity was weak, accordingly, the mass transfer efficiency was low. With the increasing of speed, the separation factor of HCE increased, the efficiency was gradually increased. However, when the speed exceeded the certain level, intensified mixed caused the poor phase separation. If the speed further increased, noise increasing and vibration intensified caused the HCE to work abnormally.

As the rotation speed was gradually improved, the loss rate of extraction agent showed a trend of first decrease and then sudden increase. In the process of improving the rotating speed, the separation ability was strong and the loss rate was small. However, once the speed exceeded the certain level, it caused the complicated vortex and turbulent easily. It led to the emulsion between light and heavy phase, which prevented the droplets coalescence and separation of two phase. Above all, the optimum of rotation speed was 2200-2600 r/min.

\subsection{Three stages counter current extraction experiment}

Theoretical calculations and experiments showed that multistage counter current extracting process was superior to multistage cross current extracting process.
Consequently, the test of extracting phenol from coal tar was carried out with the three stages counter current extraction (Table 3).

Raw oil and extraction agent entered into the centrifugal unit through the inlet at each end, then mixed thoroughly and separated efficiently, at the end, two phases flowed out from the unit through overflow vent respectively. In the whole process, extraction agent did not have to be added gradually, hence the amount of extraction agent was quite small. The three stages counter current tests were carried out at the operation condition of $29 \mathrm{~mm}$ of HWD, 1:1 of the flow ratio, $200 \mathrm{~mL} / \mathrm{min}$ of the total flow rate and $2400 \mathrm{r} / \mathrm{min}$ of the rotation speed.

The experiment results were demonstrated in Table 4. The mass transfer efficiency of three stages counter current

Table 3 Physical property parameter of raw oil and extraction agent

\begin{tabular}{llll}
\hline Item & $\begin{array}{l}\text { Density }(\mathrm{g} / \\
\left.\mathrm{cm}^{3}\right)\end{array}$ & $\begin{array}{l}\text { Viscosity } \\
(\mathrm{mPa} \mathrm{s})\end{array}$ & $\begin{array}{l}\text { Temperature } \\
\left({ }^{\circ} \mathrm{C}\right)\end{array}$ \\
\hline Raw oil & 0.9040 & 1.1752 & 25 \\
$\begin{array}{l}\text { Composite extraction } \\
\text { YH-3 }\end{array}$ & 1.0680 & 6.2143 & 25 \\
\hline
\end{tabular}


Table 4 Results of three stages counter current and single stage extraction experiment

\begin{tabular}{lll}
\hline Experiment item & $\begin{array}{l}\text { Mass transfer } \\
\text { efficiency }(\%)\end{array}$ & $\begin{array}{l}\text { Loss rate of } \\
\text { extraction agent } \\
(\%)\end{array}$ \\
\hline $\begin{array}{l}\text { Three stage counter current } \\
\text { extraction experiment }\end{array}$ & 92.6 & 0.42 \\
$\begin{array}{l}\text { Single stage extraction } \\
\text { experiment }\end{array}$ & 84.5 & 0.26 \\
\hline
\end{tabular}

test raised from $84.5 \%$ to $92.6 \%$. In the same extraction agent amount, the performance of three stages counter current test was much better than that of single stage extracting tests. However, the rate of extraction agent loss increased from $0.26 \%$ to $0.42 \%$ with increasing of extraction degree.

\section{Conclusions}

(1) Phenolic compounds were identified with $73 \%$ of the total acidic components in medium and low temperature coal tar, in which the lower-grade phenols content accounted for more than $50 \%$. The main factors affecting the purity of the extracted phenolic compounds were single or double ring aromatic hydrocarbon, such as indene, naphthalene, methylnaphthalene et al. Under the premise of high phenol extraction rate, composite $\mathrm{YH}-3$ extraction agent reduces $\pi-\pi$ interaction between phenolic compounds and aromatic hydrocarbons, thus decreasing the entrainment of neutral oil.

(2) The HCE was used in the experiment of solvent extraction phenol from coal tar. The effects of phase ratio, total flow rate and rotation speed on the process should be taken into consideration. Once one of factors exceeded the reasonable range, two-phase entrainment rate would increase dramatically, and noise increasing or intensified vibration will result in the abnormal state of the HCE. In conclusion, the optimization of operation conditions was necessary. The single stage extraction tests were carried out at $29 \mathrm{~mm}$ of HWD, 1:1-1.4:1 of the flow ratio range, $160-200 \mathrm{~mL} / \mathrm{min}$ of the total flow rate range, $2200-2600 \mathrm{r} / \mathrm{min}$ of the rotation speed range. At compatible conditions, the mass transfer efficiency was higher than $84 \%$, and the loss-extraction agent rate was lower than $0.28 \%$.

(3) Three stages counter current test showed that the mass transfer efficiency was higher than $92.6 \%$, under the optimum conditions such as HWD $29 \mathrm{~mm}$, the flow ratio $1: 1$, the total flow rate $200 \mathrm{~mL} / \mathrm{min}$ and the rotation speed $2400 \mathrm{r} / \mathrm{min}$. The rate of extraction agent loss was a little more than the single stage test, however, the integral process fully met the requirements of industrial production. Overall, phenol in coal tar could be extracted effectively by taking $\mathrm{YH}-$ 3 as extraction agent, in the process of multistage continuous count current centrifugal extraction.

Acknowledgements This study was supported by the Science and Technology Innovation Foundation of China Coal Research Institute (No. 2016ZYMS008).

Open Access This article is distributed under the terms of the Creative Commons Attribution 4.0 International License (http://crea tivecommons.org/licenses/by/4.0/), which permits unrestricted use, distribution, and reproduction in any medium, provided you give appropriate credit to the original author(s) and the source, provide a link to the Creative Commons license, and indicate if changes were made.

\section{References}

Chen CL, Zhang DY, Zhuo PZ, Chen DL, Li CX (2009) Design of small flow annular centrifugal extractor for laboratory. Fluid Mach 37(7):24-27

$\mathrm{Fu} \mathrm{AH}$ (2004) Research trends and development direction of liquidliquid mixer settle extractor. J Chem Ind Eng 25(4):9-11

Ge YZ, Jin H (1995) Recovery of phenols from coal tar and waste water by precipitation. J China Coal Soc 5:545-546

Jia YZ, Jia L (2008) The hydroxybenzene using and pick-up in coal tar. Contemp Chem Ind 37(2):194-196

Leonard RA, Chamberlain DB, Conner C (1997) Centrifugal contactors for laboratory-scale solvent extraction tests. Sep Sci Technol 32(1-4):193-210

Li Z, Yuan HX (2007) Present status and development trend of extraction apparatus. J Filtr Sep 17(4):42-45

Li J, Yao J, Wu L, Zhang XQ (2005) Development and production of new phenol product. Angang Technol 6:18-22

Li C, Liu X, Zhou ZJ, Dai ZH, Yang J, Wang FC (2016) Effect of heat treatment on structure and gasification reactivity of petroleum coke. Int J Coal Sci Technol 3(1):53-61

Liu ZL, Qang XQ (2001) Effect of phenols on stability of diesel fuel. Pet Process Sect 17(3):16-19

Liu L, Xie B (2014) Discussion on the technology of extracting phenolic compounds from coal tar. Coal Chem Ind 2:57-60

Liu F, Wang L, Yang WL, Li ZJ, Zhu YY (2012) Study on deepprocessing technology of medium and low temperature coal tar and analysis of its market prospect. Mod Chem Ind 32(7):7-11

Mishra V, Sharma M, Chakravarty S, Banerjee A (2016) Changes in organic structure and mineral phases transformation of coal during heat treatment on laboratory scale. Int J Coal Sci Technol 3(4):418-428

Tang K, Hao MM, Gan RW, Xu Y, Bai ZS (2012) Separation of trace $\mathrm{n}$-hexane from acid aqueous solution by centrifugal extraction. China Synth Fiber Ind 35(3):14-17

Tiwari KK, Sen DK (1991) Extraction of tar acids with glycols. Fuel Process Technol 28:287-300

Wang LJ (2014) A high flux centrifugal extractor. China, 203816271 
Wang JC, Tian GZ, Chen J, Song CL (2001) Application of miniature centrifugal contactors for treating high level liquid waste. Sep Sci Technol 36(13):2983-2996

Wang RC, Sun M, Liu QX, Ma YX, Feng G, Xu L, Ma XX (2011) Extraction and GC/MS analysis of phenolic compounds in low temperature coal tar from Northern Shaanxi. J China Coal Soc 36(4):664-669

Wu L, Zong ZM, Wei XY, Chen QR, Zhou GL (2001) Solvents extraction separation system of coal tar. Coal Convers 24(4):13-15

Xu JQ, Yu WD, Duan WH, Yan YY, Zhou XZ, Zhou JZ (1999) Study on treating phenolic waste water with annular centrifugal extractor. Pet Process Petrochem 30(12):46-50

Xue GF, Li LC, Xu B (1998) Development of purification treatment of coal tar at home and abroad. Coal Convers 20(2):25-28
Ye CP, Feng J, Li WY, Zhang ZH (2010) Solid phase extraction for enrichment of coal extracts phenolic compounds in coal extracts. Coal Convers 41(5):661-665

Yu WD, Duan WH, Zhang CQ, Zhou XZ, Li FQ, Zhou JZ (2001) Study of continuous countercurrent extraction of hydrocotrisone with centrifugal extractor. Fine Chem 18(10):611-613

Yuan HX, Liu J, Li Z (2010) Analysis on cyclone centrifugal extractor. Nonferrous Met 62(3):74-76

Zong ZM, Min XJ, Zhu Y, Liu SQ, Yan L, Zhao HX, Su XH, Li Y, Li ZK, Zhao YP, Fan X, Wei XY (2013) A complete equipment of extraction phenol from medium and low temperature coal tar. China, 103111088 